\title{
Design of Pump as Turbine Experimental Test Facility
}

\author{
D. L. Zariatin, Damora Rhakasywi, Fahzul Ade and Abdi Setyo \\ Mechanical Engineering Department, Universitas Pancasila, Jakarta, Indonesia
}

\begin{abstract}
This paper presents the design process of experimental test facility for pump as turbine hydropower system. Three design possibilities that related to the PAT condition of operation was developed and analyzed by using CFD Software. It is found that the First Variant with a straight flow to the PAT will produce higher velocity, which is needed to generate more rotation of the shaft generator, in order to generate more electric power. The strength of PAT construction was analyzed by using FEM software. It was found that the maximum stress is $6 \mathrm{MPa}$ and can be concluded that the construction is appropriate to the design requirement.
\end{abstract}

\section{Introduction}

Hydropower is the cleanest energy provided by nature. Utilization of hydropower system becomes worldwide, especially in the area that has the supporting resources. There are many types of turbine used in hydropower system, such as Pelton, Kaplan turbine, Francis reaction turbine, Pump as Turbine (PAT), etc. PAT technology that first introduced in 1931 [1] is one of a micro hydropower system that used an available commercial pump as a turbine in order to generate rotational movement. PAT has several advantages such as 53\% cost equipment reduction compare to another hydropower system [2], the power source availability, simple design and easy to install [3], components are available in the market [3], and long life time up to 25 years.

In order to perform researches on PAT characteristic and technology, a laboratory scale PAT installation was required. Figure 1 shows an open PAT experimental test facility used other researchers. There are two types of test facility that used by other researchers. The first type is a test facility that has a direct flow from the pump to PAT, used by Jain et al. [4], Yang et al [5], etc. The second type is a test facility that has a tank which provide a water drop from a certain height, used by Giosio et al. [6], Singh and Nestmann. [7], Suarda et al. [8].

The second type of test facility which has a reservoir tank, is considered closer to the actual condition of PAT operation. However, there might be three actual conditions that happen. First is, the condition where the area has a waterfall and the PAT could be placed right below the waterfall. The second condition might happen when the PAT could not be placed below the waterfall. The third condition might happen when there is only a water stream with certain inclination. This paper describes the design and analysis of the three conditions (Variant) mentioned by using Computational Fluid Dynamic (CFD) Software. One of the variant, which has an optimum output flow parameter was then selected and developed.

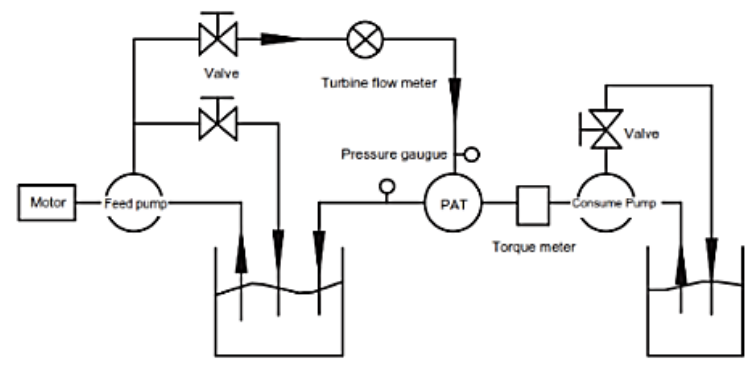

(a) Yang et al [3]

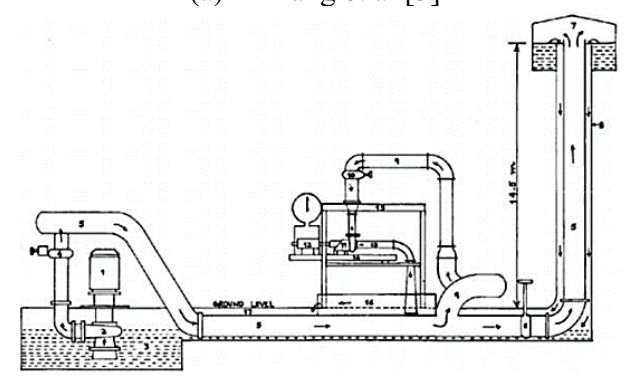

(b) Singh \& Nestmann [4]

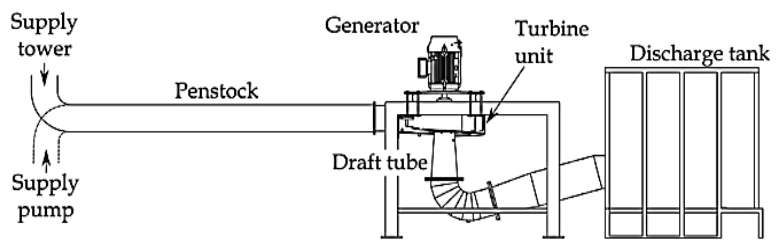

(c) Giosio et al [5]

Figure 1. Experimental test facilities used by other researchers

\section{The design}

Verien Deutscher Ingenieure 2221 (VDI 2221) design method was used in designing the PAT test facility. Three 
variants were developed in order to find the optimum installation design. The fluid flow of the design was analyzed by using CFD Software. Meanwhile the strength of PAT construction was analyzed by using a Finite Element Analysis Software.

\subsection{First variant}

Three variants were developed in order to get the best design for the experiment test facility. The first Variant has a straight flow from the tank to the pump, which used as a turbine, as shown in Figure 2. The first design condition might occur in a remote area which has a waterfall resource and the pump could place below the water reservoir tank. Clean water (assumed as $\mathrm{H}_{2} \mathrm{O}$ Constant) flows from the PVC tank into the PVC pipe. Due to the space limitation in the laboratory, the tank was placed 3.7 meters' height from the ground level. The velocity of water drop from the tank was calculated by using Equation (1). The Top Tank was designed with a volume of 640 liters, and the water density is $1000 \mathrm{~kg} / \mathrm{m}^{3}$. The inlet of the pump has a diameter size of 3 inches. A 4 inches' diameter pipe with height of 1.2 meters was used to connect the top tank and a 3 inches diameter pipe before the water flow into the pump. $\mathrm{V}$ is the flow velocity; $g$ is gravity of $9.81 \mathrm{~m} / \mathrm{s}^{2}$. The cross sectional area A of the pipes was calculated by using Equation (2) where $d$ is the diameter of pipe. $Q$ is flow-rate $\left(\mathrm{m}^{3} / \mathrm{s}\right)$. The pressure and Reynold number were calculated by using Bernoulli Equation (4) and Equation (5).

$$
\begin{aligned}
\mathrm{v} & =\sqrt{2 \cdot g \cdot Z_{1}} \\
\mathrm{~A} & =\frac{\pi}{4} d^{2} \\
\mathrm{Q} & =\mathrm{A} \mathrm{v} \\
\mathrm{P}_{1}+\frac{1}{2} \rho \quad \mathrm{V}_{1}^{2}+\mathrm{g} \mathrm{Z}_{1} & =\mathrm{P}_{2}+\frac{1}{2} \rho \mathrm{V}_{2}^{2}+\mathrm{g} \mathrm{Z}_{2}+\Delta p \\
\operatorname{Re} & =\frac{V \cdot D}{v}
\end{aligned}
$$

The calculation result found that the inlet parameters before entering the 4 inches pipe, which is velocity, pressure, and flow-rate was $8.52 \mathrm{~m} / \mathrm{s}, 137,622 \mathrm{~Pa}$, and $0.08094 \mathrm{~m}^{3} / \mathrm{s}$, respectively. These values were entered as the input parameter for flow model simulation in CFD.

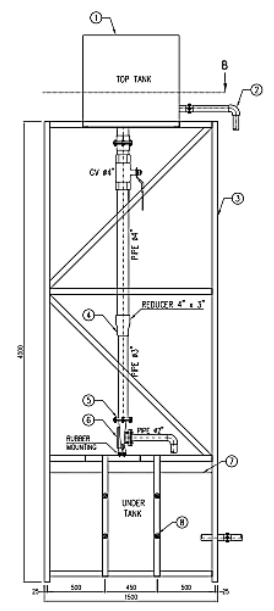

(a) Installation

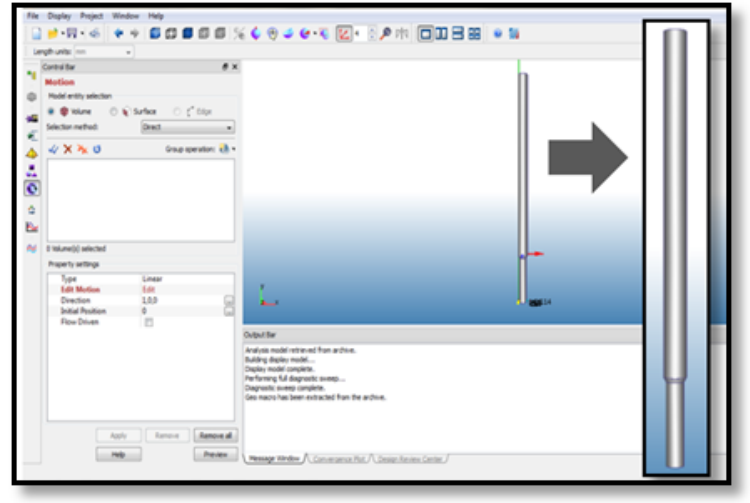

(b) Model for CFD analysis

Figure 2. First variant (a) installation, (b) model for cfd analysis

Figure 3 (a) shows the result of CFD analysis for the velocity of the water. It shows that the velocity of the water was increasing, especially at the 3 inches' diameter section (point b). Meanwhile Fig. 3 (b) shows the CFD analysis of pressure. The pressure drops in the 3 inches diameter pipe. The value of velocity, pressure and flowrate at the end of the pipe (pipe outlet = pump inlet) is $13,2671 \mathrm{~m} / \mathrm{s}, 2796.3 \mathrm{~Pa}$ and $0.0824295 \mathrm{~m}^{3} / \mathrm{s}$, respectively. The Reynold number was 1084750 , which is greater than 4000 , it is indicated the flow in the pipe was turbulent.

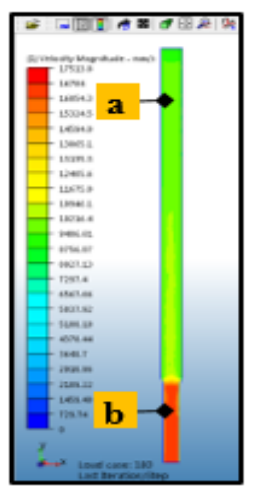

(a) Velocity

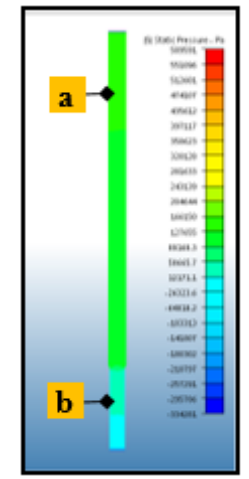

(b) Pressure
Figure 3. Result of CFD analysis of first variant; (a) velocity, (b) pressure

\subsection{Second variant}

The Second Variant has an L shape pipe joint (elbow) between the tank and a pipe that flow to the pump, as shown in Figure 4. This design condition might be happening on a remote area which has a waterfall resource, but unable to place the pump below the water reservoir tank. The input parameter was calculated by using Equation (1) - Equation (5), the same as the input parameter for the first Variant, which is $8.52 \mathrm{~m} / \mathrm{s}$, $137,622 \mathrm{~Pa}$, and $0.08094 \mathrm{~m}^{3} / \mathrm{s}$ for velocity, pressure, and flow-rate was, respectively. The CFD analysis is shown in Figure 5.

Figure 5 (a) shows that at point a, the velocity was stable and it dropped when entering the elbow (point b). The velocity raised again after leaving the elbow and keep on rising until it reached point $\mathrm{c}$ and enter the pump, which is indicated by the red colour in the flow analysis. 
Figure 5 (b) shows that the pressure was decreasing continuously. The CFD calculation result were 9.19954 $\mathrm{m} / \mathrm{s}, 3939.7 \mathrm{~Pa}, 0.0489639 \mathrm{~m}^{3} / \mathrm{s}$ for the velocity of fluid, pressure and flow-rate, respectively. The Reynold number was 700936, which indicate that the flow is turbulent.

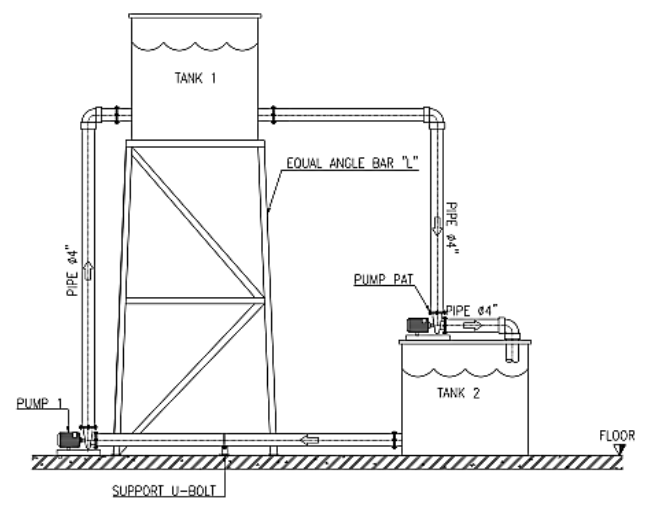

(a) Installation

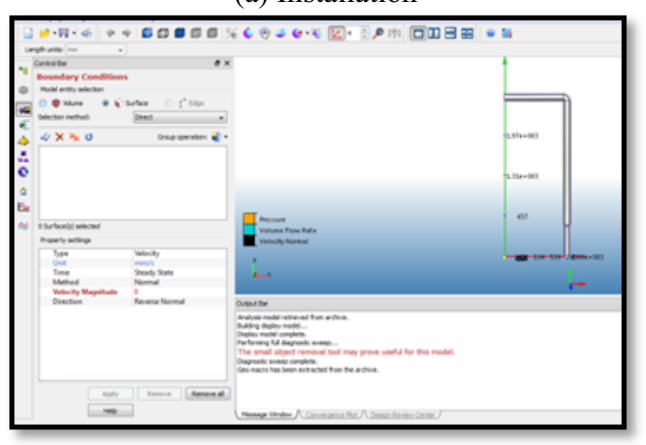

(b) Model for CFD Analysis

Figure 4. Second Variant (a) Installation (b) Model for CFD Analysis

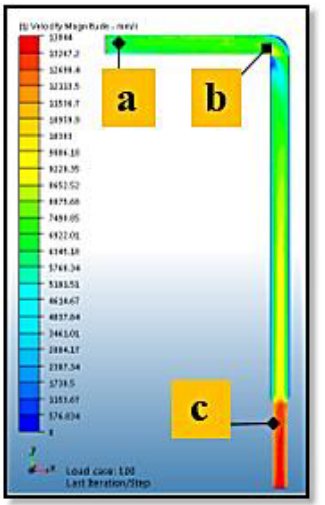

(a) Velocity contour

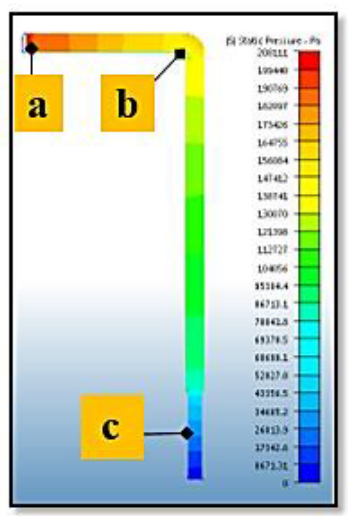

(b) Pressure Contour
Figure 5. Result of CFD analysis of second variant; (a) velocity, (b) pressure

\subsection{Third variant}

The Third Variant has a $45^{\circ}$ inclination as shown in Figure 6. This design condition might be happening in a hilly area with a certain inclination on the landscape and has no waterfall resource.

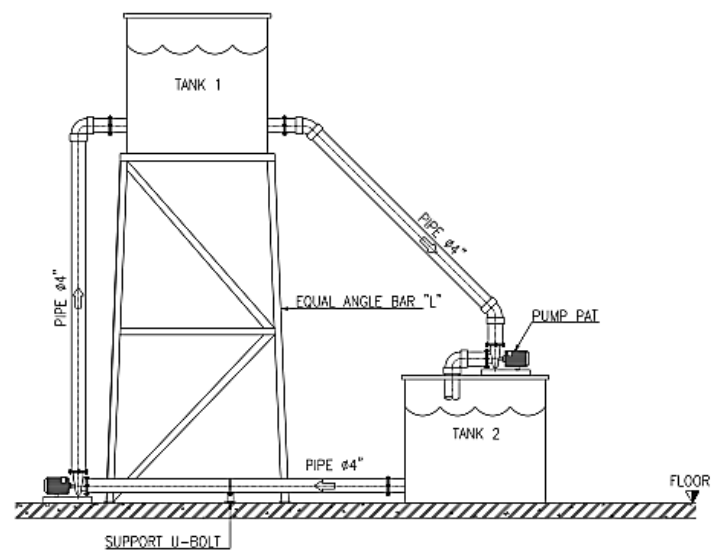

(a) Installation

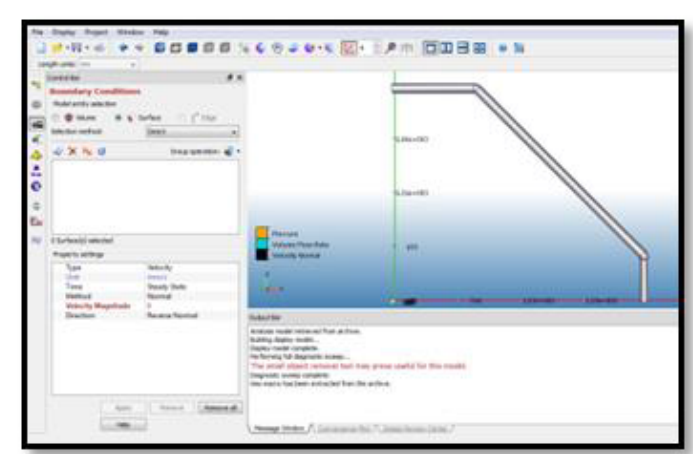

(b) Model for CFD Analysis

Figure 6. Third variant (a) installation (b) model for CFD analysis

Figure 7 (a) shows that the velocity increased as the fluid entering the elbow (point a). The greatest velocity occurred on point $\mathrm{c}$ as the cross sectional area reduced from 4 inches to 3 inches. Meanwhile Figure 7 (b) shows the pressure drop along the $45^{\circ}$ inclined pipe. The velocity, pressure and flow-rate is $6,46684 \mathrm{~m} / \mathrm{s}, 9564.2 \mathrm{~Pa}$, $0.0394708 \mathrm{~m}^{3} / \mathrm{s}$, respectively. The flow was turbulence which is indicated by the Reynold Number by 406768 .

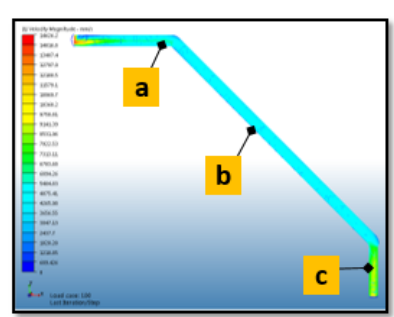

(a) Velocity

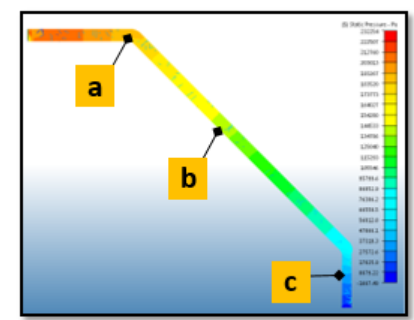

(b) Pressure
Figure 7. Result of CFD analysis of Third Variant; (a) Velocity contour, (b) Pressure Contour.

Table 1. CFD calculation result

\begin{tabular}{|c|c|c|c|c|}
\hline Variant & $\begin{array}{c}\text { Velocity } \\
(\mathrm{m} / \mathrm{s})\end{array}$ & $\begin{array}{c}\text { Pressure } \\
(\mathrm{Pa})\end{array}$ & $\begin{array}{c}\text { Flow-rate } \\
\left(\mathrm{m}^{3} / \mathrm{s}\right)\end{array}$ & $\begin{array}{c}\text { Reynold } \\
\text { Number }\end{array}$ \\
\hline 1 & 13.2853 & 2796.3 & 0.082429 & 1084750 \\
\hline 2 & 9.19954 & 3939.7 & 0.048963 & 700936 \\
\hline 3 & 6,46684 & 9564.2 & 0.039470 & 406768 \\
\hline
\end{tabular}




\section{Design implementation}

Figure 8 shows the implementation of experimental test facility that designed and analysed by CFD software. Various condition was performed to acknowledge the power that generated by the PAT generator. The construction of the experimental test facility was made of St-37, L shape with dimension of $50 \times 50 \mathrm{~mm}$ and thickness of $4.62 \mathrm{~mm}$. In order to estimate the strength of the installation, FEM was performed as shown in Figure $8(\mathrm{~b})$. It is found that the maximum stress on the construction is $6.62 \mathrm{MPa}$ and considered safe for the experimental facility.

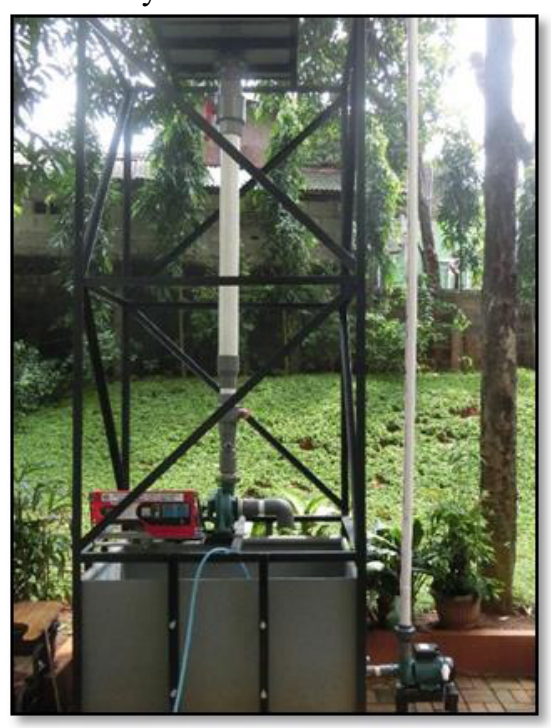

(a) Experimental test facility

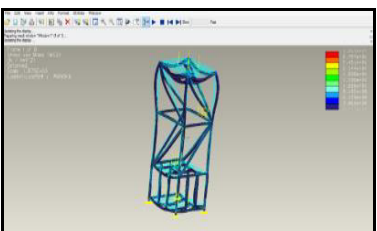

(b) Construction's strength analysis

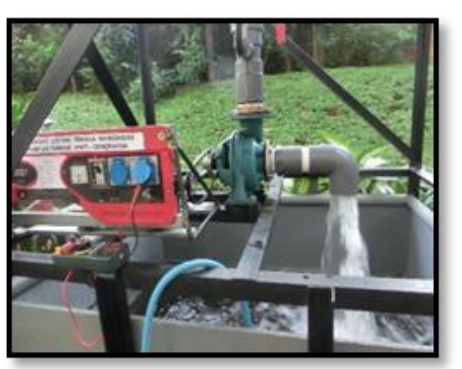

(c) Measurement equipment

Figure 8. The PAT experimental test facility

\section{Conclusion}

In developing the experimental test facility, three variants that represent the possible conditions of the PAT working area were designed and analysed by using a CFD software and calculation. It is found that the first Variant, which has a straight flow is the best design among two others. First Variant has the highest velocity of 13.2853 $\mathrm{m} / \mathrm{s}$ and flow-rate of $0.0824295 \mathrm{~m}^{3} / \mathrm{s}$. The second has a velocity of $9.19954 \mathrm{~m} / \mathrm{s}$ and flow-rate of $0.0489639 \mathrm{~m}^{3} / \mathrm{s}$. Meanwhile the third Variant has velocity of $6,46684 \mathrm{~m} / \mathrm{s}$, and flow-rate of $0.0394708 \mathrm{~m} 3 / \mathrm{s}$. The First Variant has the lowest pressure compare to second and third Variant, which are 2796.3 $\mathrm{Pa}, 3939.7 \mathrm{~Pa}$, and 9564.2 $\mathrm{Pa}$, respectively. All of three Variant has a turbulent flow, according to their Reynold number, which is 1084750 , 700936, and 406768. By comparing these parameter, it concludes that the first Variant is the best choice.

The construction was made by using $\mathrm{L}$ shape scaffold from St 37 with $4.62 \mathrm{~mm}$ thickness and $50 \mathrm{~mm}$ width. The strength of the construction was analysed by using FEM software. It was found that the maximum stress is 6 $\mathrm{MPa}$. It can be concluded that the construction is appropriate to the design requirement.

\section{References}

1. A. Elbratran, O. Yaakob, Y. M. Ahmed and H. Shabara, "Operation, performance and economic analysis of low head micro-hydropower turbines for rural and remote areas: A review," Renewable and Sustainable Energy Reviews, vol. 43, no. 1, pp. 40$50,(2015)$

2. M. Arriaga, "Pump as turbine - A pico-hydro alternative in Lao People's Democratic Republic," Renewable Energy, vol. 35, pp. 1109-1115, (2010)

3. S. V. Jain and R. N. Patel, "Investigations on pump running in turbine mode : A review of the state-ofthe-art," Renewable and Sustainable Energy Reviews, vol. 30, pp. 841-868, (2014)

4. S. V. Jain, A. Swarnkar, K. H. Motwani and R. N. Patel, "Effect of impeller diameter and rotational speed on performance of pump running in turbine mode.," Energy Conversion and Management, vol. 89, no. 1, pp. 808-824, (2015)

5. "Numerical Research on Effect of Splitter Blades to the Influence of Pump as Turbine," International Journal of Rotating Machinery, vol. 2012, no. 1, p. 9, (2012)

6. D. Giosio, A. Henderson, P. Walker, J. Sargison and P. Gautam, "Design and perfomance evaluation of a pump-as-turbine micryo-hydro test facility with incorporated inlet flow control," vol. 78, (2015)

7. P. Singh and F. Nestmann, "Internal hydraulic analysis of impeller rounding in centrifugal pumps as turbines," Experimental Thermal and Fluid Science, vol. 35, no. 1, pp. 121-134, (Januari 2011)

8. M. Suarda, N. Suarnadwipa and W. B. Adnyana, "Experimental Work on Modification of Impeller Tips of a Centrifugal Pump as Turbine," in The 2nd Joint International Conference on "Sustainable Energy and Environment (SEE 2006)", Bangkok, Thailand, (2006)

9. Y. Sun-Sheng, K. Fan-Yu, J. Wan-Ming and Q. Xiao-Yun, "Effects of Impeller Trimming Influencing Pump as Turbine," Computer \& Fluids, vol. 67, pp. 72-78, (Agustus 2012) 